\title{
Microphysical, macrophysical and radiative signatures of volcanic aerosols in trade wind cumulus observed by the A-Train
}

\author{
T. Yuan ${ }^{1,2}$, L. A. Remer ${ }^{2}$, and H. Yu ${ }^{2,3}$ \\ ${ }^{1}$ Joint Center for Earth Systems Technology, University of Maryland, Baltimore County, Baltimore, MD, USA \\ ${ }^{2}$ Laboratory for Atmospheres, NASA Goddard Space Flight Center, Greenbelt, MD, USA \\ ${ }^{3}$ Earth System Science Interdisciplinary Center, University of Maryland, College Park, MD, USA
}

Received: 8 February 2011 - Published in Atmos. Chem. Phys. Discuss.: 23 February 2011

Revised: 1 July 2011 - Accepted: 8 July 2011 - Published: 21 July 2011

\begin{abstract}
Increased aerosol concentrations can raise planetary albedo not only by reflecting sunlight and increasing cloud albedo, but also by changing cloud amount. However, detecting aerosol effect on cloud amount has been elusive to both observations and modeling due to potential buffering mechanisms and convolution of meteorology. Here through a natural experiment provided by long-term degassing of a low-lying volcano and use of A-Train satellite observations, we show modifications of trade cumulus cloud fields including decreased droplet size, decreased precipitation efficiency and increased cloud amount are associated with volcanic aerosols. In addition we find significantly higher cloud tops for polluted clouds. We demonstrate that the observed microphysical and macrophysical changes cannot be explained by synoptic meteorology or the orographic effect of the Hawaiian Islands. The "total shortwave aerosol forcin", resulting from direct and indirect forcings including both cloud albedo and cloud amount, is almost an order of magnitude higher than aerosol direct forcing alone. Furthermore, the precipitation reduction associated with enhanced aerosol leads to large changes in the energetics of air-sea exchange and trade wind boundary layer. Our results represent the first observational evidence of large-scale increase of cloud amount due to aerosols in a trade cumulus regime, which can be used to constrain the representation of aerosol-cloud interactions in climate models. The findings also have implications for volcano-climate interactions and climate mitigation research.
\end{abstract}

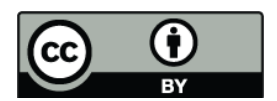

Correspondence to: T. Yuan (tianle.yuan@nasa.gov)

\section{Introduction}

Aerosols directly modify planetary albedo by absorbing and scattering solar radiation often referred to as the "aerosol direct effect" (McCormic and Ludwig, 1967). Increased aerosols are also expected to increase cloud droplet concentration, total droplet cross-sectional area and therefore cloud albedo for warm clouds, labeled the Twomey effect (Twomey, 1977). Moreover, increased aerosol concentration can enhance cloud macro-physical properties such as cloud amount (referred to as "cloud amount effect" here) and cloud organization (Albrecht, 1989; Stevens and Feingold, 2009; Feingold et al., 2010). Both the Twomey effect and cloud amount effect are collectively referred to as aerosol indirect effects. Aerosol direct and indirect effects constitute a strong yet still highly uncertain forcing to the climate system in a global sense (Anderson et al., 2003; Forster et al., 2007). Estimating the combined direct and indirect aerosol forcing, especially the indirect component, with sufficiently narrow error bars remains one of the largest challenges for understanding climate change.

The cloud amount effect is built upon this chain of events: enhanced aerosol loading increases warm cloud droplet number concentration and decreases droplet size (Twomey, 1977; Heymsfield and McFarquhar, 2001), an increase in droplet number decreases precipitation efficiency (Albrecht, 1989; Rosenfeld, 1999; Andreae et al., 2004), and cloud amount increases with decreasing precipitation efficiency (Albrecht, 1989). While the Twomey effect on warm clouds has been well documented, the cloud amount effect has eluded efforts of observational detection and attribution since its original proposal (Albrecht, 1989), which contributes critically to the current uncertainty. This is because a myriad of processes and factors such as entrainment, droplet sedimentation, time

Published by Copernicus Publications on behalf of the European Geosciences Union. 
scale and cloud scale dynamics can counteract the proposed chain reaction and result in unexpected changes in cloud macro-properties due to increased aerosols (Stevens et al., 1998; Ackerman et al., 2004; Bretherton et al., 2007; Wood, 2007; Feingold et al., 1996; Lu and Seinfeld, 2005; Xue and Feingold, 2006). Moreover, for observed correlations between aerosols and cloud amount, alternative explanations such as co-varying meteorology and retrieval artifacts can be proposed that do not invoke physical connections between aerosol and clouds (Brenguier et al., 2003; Mauger and Norris, 2007; Rauber et al., 2007; Loeb and Schuster, 2008; Yuan et al., 2008; Quaas et al., 2009). A multi-model comparison study also highlights the difficulty and uncertainty in modeling this effect in general circulation models (Quaas et al., 2009). Stevens and Feingold (2009) provide an excellent overview of the complexity and subtlety related to the cloud amount effect.

Most previous studies of cloud amount effect have focused on stratocumulus clouds because of their high cloud fraction and extensive coverage. Trade cumulus clouds as the other major oceanic warm cloud regime are relatively underinvestigated. However, trade cumulus can be found over larger areas as compared to stratocumulus although cloud fraction is lower (Norris and Slingo, 2009). More importantly, the cloud amount effect (or indirect effects in general) may depend on cloud regimes (Stevens and Feingold, 2009). It is thus suggested that an ideal way to study aerosol indirect effects is through the use of natural experiments focusing on a particular cloud regime (Stevens and Feingold, 2009). In this study we explore aerosol effects on trade cumulus clouds.

In this study we present results on aerosol cloud amount effect caused by a long-lasting volcanic degassing event. We will document the observed changes in cloud and precipitation properties related to cloud amount effect. The rest of the paper is organized as follows. In Sects. 2 and 3 we will describe the volcanic event, and then the data and methods of analysis, respectively. In Sect. 4, we will present results. Discussions of possible orographic effects and further evidence for aerosol effects will be presented in Sect. 5. Conclusions and final remarks will be presented in Sect. 6 .

\section{The natural experiment}

The Halemaumau Crater of the Kilauea volcano on the Big Island of Hawaii $\left(19^{\circ} 34^{\prime} \mathrm{N}, 155^{\circ} 30^{\prime} \mathrm{W}\right)$ has been active since March 2008. The volcano is actively degassing sulfur dioxide from the crater vent, located at an altitude of $1200 \mathrm{~m}$. The gas is carried downwind and forms a large plume of sulfate aerosols reaching as far as $6000 \mathrm{~km}$ downwind as shown in Fig. 1. Cloud-Aerosol Lidar with Orthogonal Polarization (CALIOP) data show that the aerosol plume stays within the lowest $2 \mathrm{~km}$ layer.
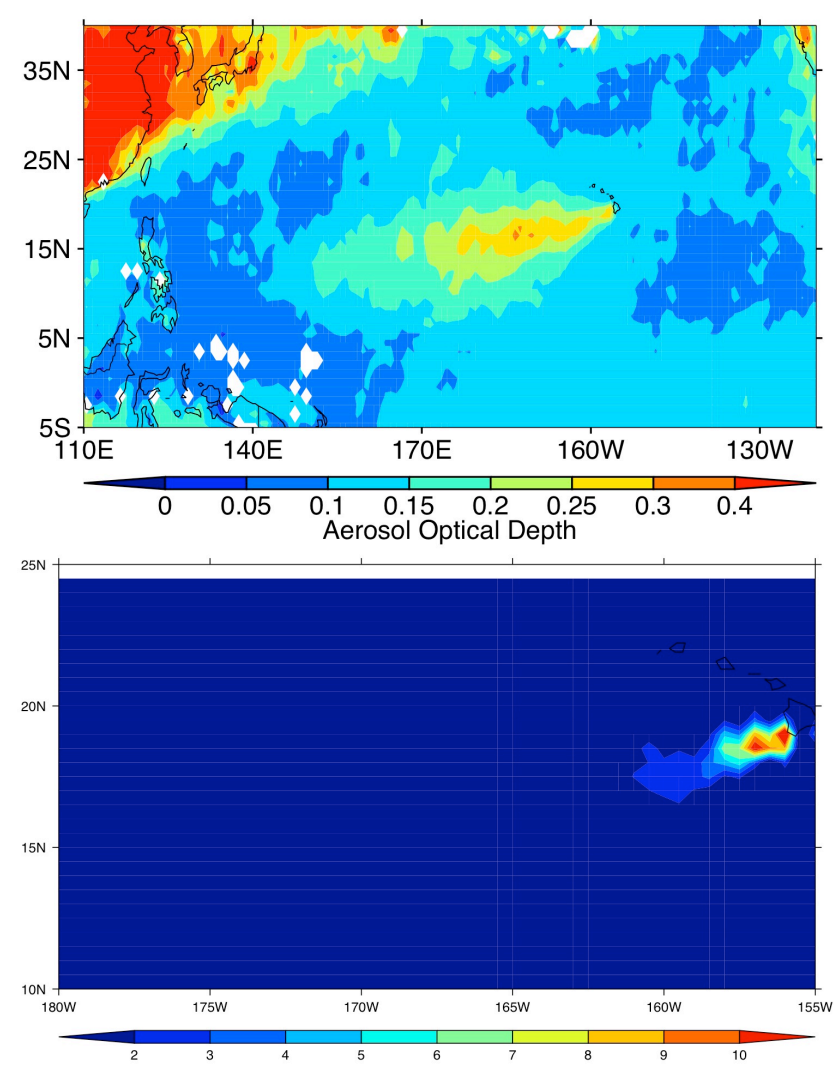

Fig. 1. The plume originating from the Halemaumau Crater of the Kilauea volcano on the Big Island of Hawaii $\left(19^{\circ} 34^{\prime} \mathrm{N}, 155^{\circ} 30^{\prime} \mathrm{W}\right)$ as evidenced in (a) MODIS aerosol optical depth and (b) $\mathrm{OMI} \mathrm{SO}_{2}$ (in Dobson Unit) maps averaged over June, July, August 2008. The plume of aerosol optical depth extends as far as the Marshall Islands. The plume of $\mathrm{SO}_{2}$ is less extensive presumably because of the transformation of $\mathrm{SO}_{2}$ into sulfate particles during the course of transport.

The volcanic degassing of Halemaumau creates a natural laboratory where we can observe the consequences of adding aerosols to a relatively clean boundary layer over a broad region and during a long time period. Anthropogenic aerosols have minimal impact on this region in the summer due to the strong subtropical high-pressure system and weak source strength from Hawaii. The background aerosol loading of this region is very low (Fig. 1). The non-absorbing nature of volcanically produced sulfate aerosols avoids the complication from aerosol absorption (Ackerman et al., 2000; Koren et al., 2004; Kaufman and Koren, 2006; Feingold and Siebert, 2009). Most importantly, the volcanic activity producing the aerosol plume is entirely independent of air mass properties (Gasso, 2008). We can thus largely avoid the important problem of spurious correlation between observed aerosol and cloud properties created by the co-varying large-scale meteorology (Brenguier et al., 2003; Lohmann et al., 2006; Loeb and Schuster, 2008; Stevens and Feingold, 2009). 
The added bonus of this natural experiment is the predominance of the remarkably homogeneous trade wind circulation in the area (Riehl et al., 1951; Betts and Albrecht, 1987), with a possible exception discussed later. The almost Gaussian shaped aerosol plume emanating from the volcano source provides strong testimony to the steady wind and diffusive nature of the mixing in this region (Fig. 1). These homogeneous background conditions coupled with the volcanic aerosol source are used to identify aerosol effects by comparing the plume-affected area and nearby non-affected area. The aerosol is there because the volcano puts the particles there. There is no reason to expect the atmosphere laterally outside of the plume to be different than within the plume, except for the introduction of the $\mathrm{SO}_{2}$ and subsequent production of sulfate particles. Here we have a controlled natural experiment in which non-absorbing sulfate aerosols are introduced to an otherwise pristine trade wind boundary layer, where the direct and indirect effects can be tracked and quantified. We focus on the warm trade cumuli in the summer to limit the impact of intrusions of tropical and mid-latitude storm track clouds. We diagnose the effect of aerosols on trade cumulus clouds in two ways: in one we compare cloud properties inside and outside aerosol plume and in the other we compare cloud properties in 2008 with other years.

The Hawaiian Islands, however, do introduce orographic effects due to their high elevation. These orographic effects can be categorized into two types: near field (local) and farfield (Xie et al., 2001). The local effect will appear on the lee side of the islands with anomalously low cloud amount (shown latter). The far-field response results from more subtle air-sea interactions. The blocking of tall mountains on the islands introduces a semi-stationary wind stress curl on the ocean surface downwind. This wind stress curl excites ocean Rossby waves that lead to a SST warm tongue feature centered near $19^{\circ} \mathrm{N}$. The warm SST anomaly introduced by this effect is on the order of $0.1^{\circ} \mathrm{C}$ (Hafner and Xie, 2003). We will specifically analyze the impact of this far-field orographic effect (referred to as "wake effect" in this paper for convenience) on our results and show it does not affect our results.

\section{Data and method}

A suite of data sets from the NASA A-Train satellites (Stephens et al., 2002) is used here to examine the chain reactions associated with the cloud amount effect. Aerosol loading is characterized by aerosol optical depth, Angstrom exponent and aerosol index (here taken as simply a product of aerosol optical depth and Angstrom exponent) using the collection 5 aerosol product from the MODerate resolution Imaging Spectroradiometer (MODIS) aboard the Terra and Aqua satellites (Remer et al., 2005). We mostly use data over ocean and both level-2 granule data at $10-\mathrm{km}$ resolution and level-3 monthly products at 1-degree resolution are used in our study. The collection 5 cloud product (Platnick et al., 2003) from MODIS is analyzed to study cloud microand macro- physical properties as well as optical properties. The physical retrieval variables used in the analysis include cloud fraction, cloud optical depth and cloud effective radius. Both level-2 granule data and level-3 monthly data are used in this study. Auxiliary MODIS visible images and cloud mask data are used as well. We note that potential retrieval errors in cloud product due to the presence of aerosols and $\mathrm{SO}_{2}$ is negligible compared to the signal of aerosol effect on clouds as we will show later.

Warm cloud precipitation is characterized by the CloudSat precipitation product (Haynes et al., 2009). We note that in this retrieval algorithm precipitation is detected and quantified using the radar path-integrated attenuation in contrast to the traditional method based on the relationship between radar reflectivity and precipitation rate. This path-integrated attenuation derived precipitation does not have verticallyresolved precipitation information. Instead it is a column integrated measure. Currently, we only use data over ocean since this method requires a good characterization of the surface radar reflectivity and ocean surface is more easily characterized. Refer to Haynes et al. (2009) for more information on the details of the retrievals. Cloud-Aerosol Lidar with Orthogonal Polarization (CALIOP) provides the vertical distribution of cloud and aerosols, which are crucial to ensure that aerosols and clouds are indeed interacting. We used the CALIOP cloud and aerosol layer product to get vertical aerosol distributions as well as cloud top information for accurately estimating the height of warm trade cumuli tops. The Clouds and the Earth's Radiation Energy System (CERES) provides estimates of broadband shortwave and longwave fluxes at the top of the atmosphere (Wielicki et al., 1996). We use the $2.5^{\circ} \times 2.5^{\circ}$ "ERBE-like" monthly product to estimate broadband shortwave flux. In addition to satellite data sets, we also use meteorological fields from the NASA Modern Era Retrospective-Analysis for Research and Applications (MERRA) project. The MetOffice HadISST 1.1 global, monthly sea surface temperature data are used to characterize sea surface changes.

In light of the recent realization of the aerosol-cloud continuum or "twilight zone" (Charlson et al., 2007; Koren et al., 2007), we will try to estimate the overall aerosol effect on the shortwave radiation field without a separation of cloudy and clear scenes in addition to the usual approach of analyzing changes in "cloudy" pixels associated with aerosols. In this approach we directly observe the broadband shortwave albedo (or flux) changes of the entire aerosol-cloud continuum resulting from aerosol perturbations, thereby bundling direct and indirect effects into one holistic measure of the aerosol total radiative forcing.

We derive individual cloud sizes from the MODIS level2 cloud mask product to study cloud macrophysical changes caused by aerosols. Using an automatic algorithm we find patches of connected cloudy pixels (each patch defined as 

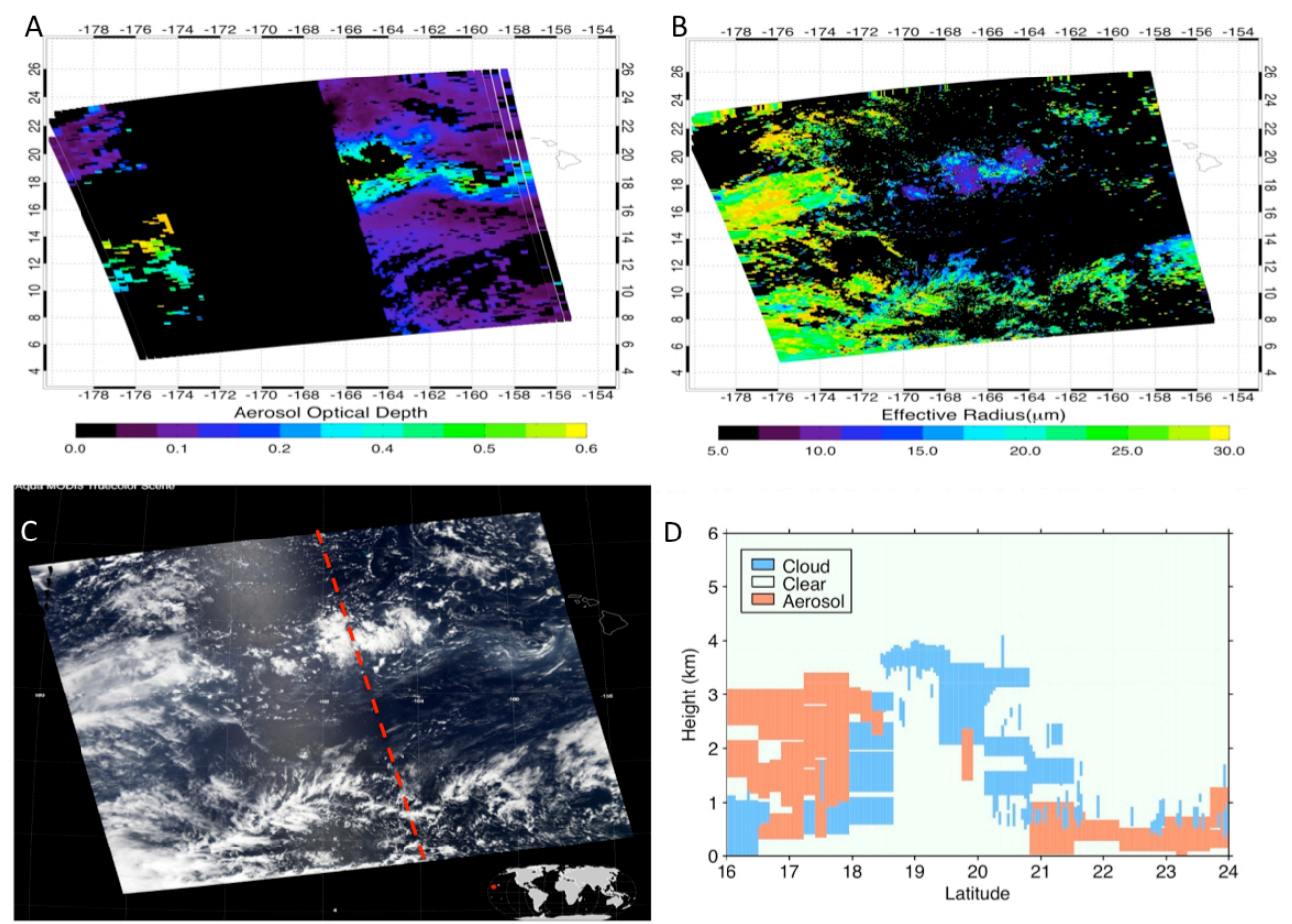

Fig. 2. The 17 July 2008 case of volcanic aerosol interacting with clouds: (a) MODIS level-2 aerosol optical depth at 550 nm; (b) MODIS cloud droplet effective radius $(\mu \mathrm{m})$; (c) MODIS visible image with the CALIPSO ground track overlaid; and (d) CALIPSO feature mask identifying the aerosol plume and interacting clouds from $16^{\circ} \mathrm{N}$ to $24^{\circ} \mathrm{N}$. A clear reduction of droplet size is visible inside the high aerosol optical depth areas. The gap in the middle of (a) is caused by sun-glint that is avoided by the current MODIS aerosol algorithm.

a "cloud") inside each granule and record the size (simply the number of pixels inside each cloud) and location of each cloud. We do not include pixels that are connected diagonally (4-neighbor connectivity) although the results are not sensitive to this choice. We can then calculate mean cloud size for a specific area and season. Any cloud that contains cirrus or non-liquid cloudy pixels (as indicated by the MODIS thermodynamic phase) is discarded in our analysis. For each season we find on the order of 100,000 liquid only clouds that are larger than 4 pixels in our study area.

\section{Results}

\subsection{An illustrating case study}

We illustrate an example of volcanic aerosols affecting clouds in Fig. 2. The Ozone Monitoring Instrument (OMI) observed strong $\mathrm{SO}_{2}$ degassing on 16 and 17 July 2008. The $\mathrm{SO}_{2}$ subsequently converts into sulfates and a plume of sulfates is clearly visible in the Moderate Resolution Imaging Spectroradiometer (MODIS) aerosol optical depth (Remer et al., 2005) map on 17 July 2008 (Fig. 2a). A patch of clouds downwind of the Big Island formed within the sulfate plume (Fig. 2b and c). A track of the CALIOP cut through this cloud patch (red line in Fig. 2c). CALIOP feature mask clearly in- dicates that the aerosol layer was confined within the boundary layer and intertwined with clouds (Fig. 2d). These 3dimensional anatomies of aerosols and clouds by the A-Train sensors strongly indicate that aerosols and clouds were interacting with each other. As a result, relative to the background value of $18 \mu \mathrm{m}$ cloud droplet effective radius was reduced by more than $5 \mu \mathrm{m}$ (Fig. $2 \mathrm{~b}$ ) for clouds within the sulfate plume. A large number of similar cases using combinations of ATrain data sets reach the same conclusion. In the following we show systematic impacts of the volcanic aerosols on ensembles of trade cumuli at large spatial and long temporal scales and assess their consequences.

\subsection{Aerosol effects on the cloud ensemble}

Figure 3a shows a map of MODIS-derived seasonal mean aerosol index (Nakajima et al., 2001) (here taken as the product of aerosol optical depth and Angstrom exponent). The volcanic sulfate aerosols stand out immediately as a plume of high aerosol index (Fig. 3a). We use level-2 MODIS cloud retrievals (Platnick et al., 2003) to assess the impact of added volcanic sulfate aerosols, active cloud condensation nuclei $(\mathrm{CCN})$. We note that trade cumulus clouds are often broken and small in horizontal scale (Xue and Feingold, 2006; Zhao and Di Girolamo, 2007) and they create a challenging environment for MODIS retrievals (Koren et al., 2007; Marshak 

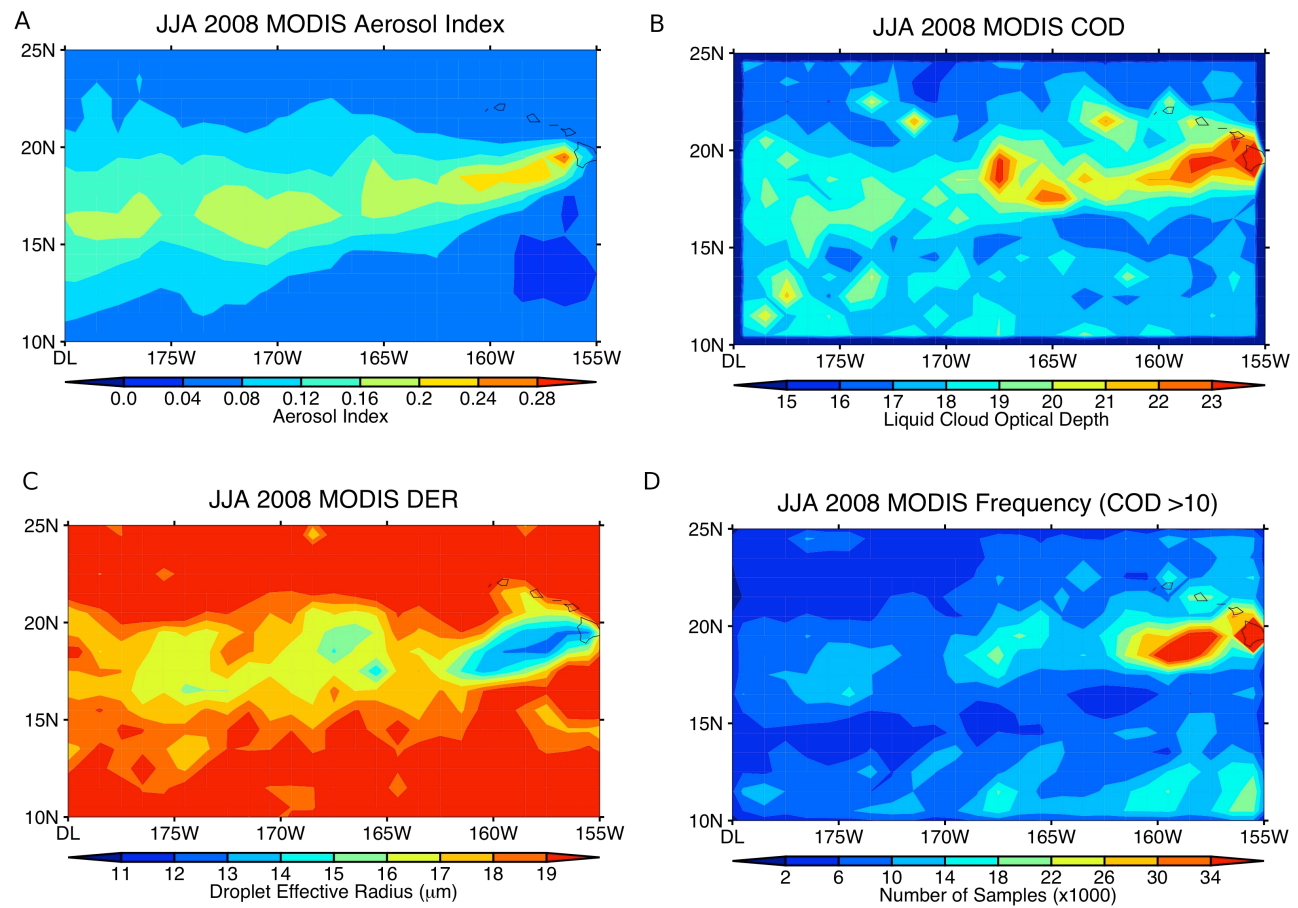

D

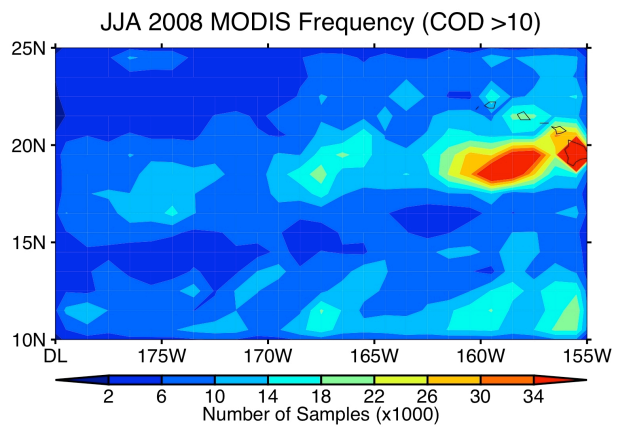

Fig. 3. Distributions of (A) aerosol index defined as aerosol optical depth multiplied by the Angstrom exponent; (B) cloud optical depth (COD); (C) droplet effective radius (DER); and (D) filtered cloudy pixel frequency averaged over June, July, and August, 2008, showing volcanic tracks over the course of the season. All parameters are derived from the level-2 MODIS data. Cloud products are for liquid clouds with optical depth greater than 10 .

et al., 2006; Wen et al., 2006; Charlson et al., 2007; Yuan et al., 2008). A series of quality control filters are thus applied to the original MODIS cloud data to minimize the chance of artificial correlations between aerosols and clouds (Yuan et al., 2008). Briefly speaking, we include only pixels that have optical depth greater than 10 , brightness temperature greater than $270 \mathrm{~K}$, the cloud phase is flagged as liquid, and the cloudiness quality flag denotes "overcast" with the highest confidence (Yuan et al., 2008). The resulting June-JulyAugust (JJA) average cloud optical depth map is shown in Fig. 3b. For clouds inside the plume, the mean cloud optical depth increases from the background value, north and south of the sulfate plume, by up to 9 . Correspondingly, cloud droplet effective radius decreases by 3 to $8 \mu \mathrm{m}$ for clouds inside the sulfate plume depending on the location (Fig. 3c). Both the enhancement in cloud optical depth and reduction in cloud droplet size manifest themselves as distinct "volcano tracks" that correspond well to the sulfate plume. These cloud microphysical and optical property changes associated with the volcanic aerosol plume support the Twomey effect and complete the first link in the chain reaction associated with the cloud amount effect.

The occurrence of filtered cloudy pixels increases by up to a factor of 5 within the plume compared to the background as shown in Fig. 3d. Within the sulfate plume we note a remarkable correspondence among cloud optical depth, cloud droplet size and number frequency (defined as the number of qualified level-2 pixels in a grid box): the loci of primary, secondary and tertiary peaks of cloud optical depth correspond well to those of cloud droplet size and number frequency. These observations imply that changes in cloud optical depth and cloud droplet size are associated with increases in number frequency. Repeated analyses with different cloud optical depth thresholds reach the same conclusion, suggesting the effect spans the entire cloud spectrum. We also look at the cloud fraction data directly (including all cloudy pixels by cloud mask without filtering). As shown in Fig. 4, the overall MODIS cloud fraction within the sulfate plume increases by up to $25 \%$ from the background values of around 0.44. As an attempt at roughly quantifying the connection between aerosol and liquid cloud fraction we use seven years of data from Aqua MODIS. We normalize each $1^{\circ} \times 1^{\circ}$ cloud and aerosol monthly grid during JJA of 20032009 and plot the normalized cloud fraction against normalized aerosol index in Fig. 5. In the normalization, cloud fraction in each $1^{\circ}$ box is divided by mean cloud fraction of a clean, background area $\left(20-25^{\circ} \mathrm{N}\right.$ and $165-170^{\circ} \mathrm{W}$ in our case). The normalization is done for multi-year data in order to remove interannual variation from large-scale conditions and possible calibration drift in the MODIS sensor that might introduce artificial trends in the retrieved products. Figure 5 suggests that for a doubling of aerosol concentration 


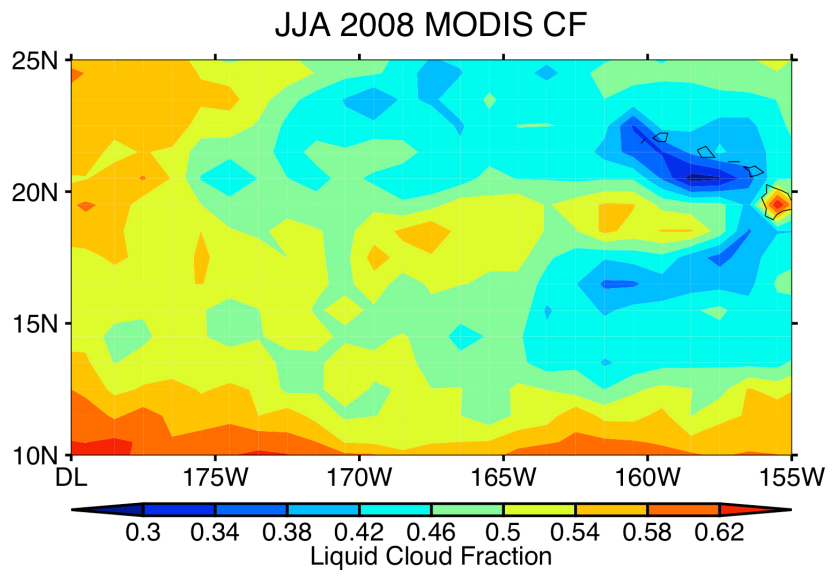

Fig. 4. Same as Fig. 3d, except level-3 cloud fraction is used instead of cloud occurrence frequency. The local orographic effect is apparent in this figure. The lee-side of the islands has anomalously low cloud fraction.

we observe an increase of $10 \%$ in cloud fraction based on the multi-year data. This is comparable to the inference based on 2008 alone by contrasting cloud fraction inside and outside of plume.

We use the t-student test to evaluate the statistical significance of the changes in cloud properties such as optical depth, droplet effective radius, and cloud occurrence. Most of the changes inside the volcano tracks are statistically significant at the $95 \%$ or greater level. We also examined if these volcano tracks stand out in a climatological sense: are the cloud and aerosol properties significantly different (above or below) in a statistical sense from the climatological mean using Terra's 11 year data record? An example is shown in Fig. 6 for cloud optical depth. The shaded contours represent the magnitude of normalized (in the same way as cloud fraction) cloud optical depth 2008 - cloud optical depth $\mathrm{h}_{\text {mean }}$ and the dotted areas indicate that the difference is statistically significant at the $95 \%$ level. Again, we see three local maxima of cloud optical depth and they are all statistically significantly higher than climatological mean. Similar results are obtained for droplet effective radius, cloud fraction, and aerosol optical depth. Qualitatively similar results are obtained if normalization is not applied.

The positive anomaly in cloud fraction both relative to the background and to climatology suggests that the large injection of volcanic sulfates increases the trade cumulus cloud fraction. The decoupling of volcanic degassing from meteorology further strengthens the physical connection between aerosols and cloud fraction. These observations of sulfateinduced increased cloud fraction support the third link in the chain reaction. The missing link, thus, is the critical precipitation connection.

While many past studies often assume trade cumuli are non-precipitating for simplicity, more recent observa-

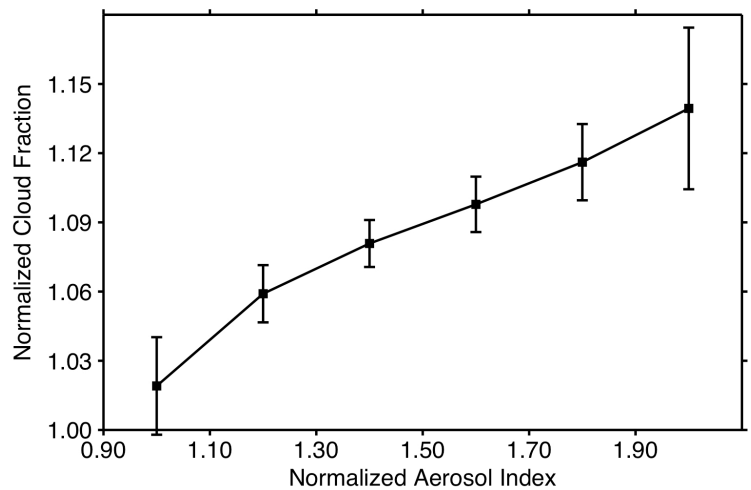

Fig. 5. The relationship between normalized cloud fraction and normalized aerosol index calculated from $1^{\circ}$ Level 3 monthly data from a 7 year record of June-July-August Aqua products. "Normalization" indicates that each 1 degree square in the monthly image was divided by the values from a clean reference area in that year. The reference area representing clean conditions is $\left[20-25^{\circ} \mathrm{N}\right.$, $165-170^{\circ} \mathrm{W}$. Normalization is required in a multi-year analysis because clean conditions change year by year either because of large-scale meteorology or possible drift in the MODIS products due to calibration. The plot suggests that doubling aerosol index leads to about a $10 \%$ increase in cloud amount. The error bars stand for the standard deviation of the normalized cloud fraction in each aerosol index bin.

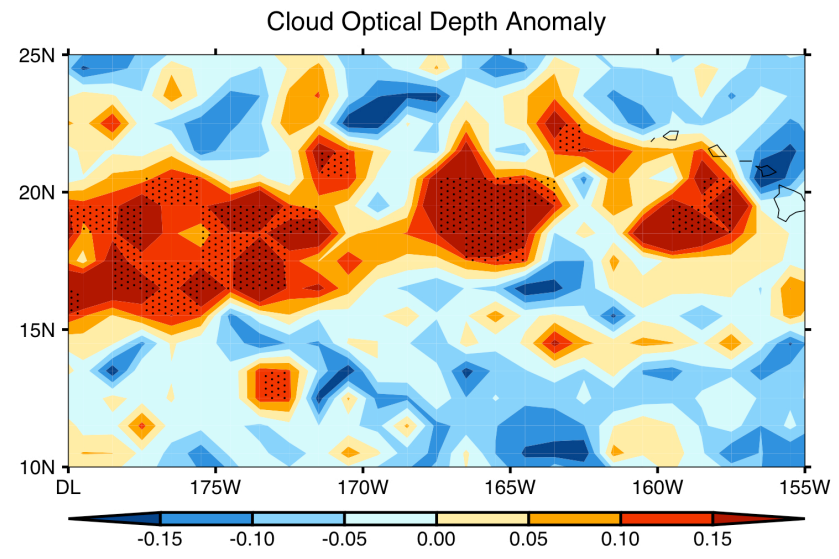

Fig. 6. The anomaly of normalized cloud optical depth in June-July-August 2008, relative to the climatology of JJA from 2000 to 2010. The dotted areas represent areas where cloud optical depth is statistically significantly $(95 \%)$ higher than the mean.

tions indicate these clouds often precipitate (Rauber et al., 2007; Snodgrass et al., 2009). Furthermore, precipitation is increasingly recognized as a crucial process that links cloud microphysical properties with macro-properties such as cloud fraction and morphology (Rauber et al., 2007; Xue et al., 2008; Stevens and Feingold, 2009). We examine latitudinal cloud and precipitation changes in an area between $160^{\circ} \mathrm{W}$ and $170^{\circ} \mathrm{W}$ and between $10^{\circ} \mathrm{N}$ and $25^{\circ} \mathrm{N}$, selected to further constrain the large scale conditions. Results are 

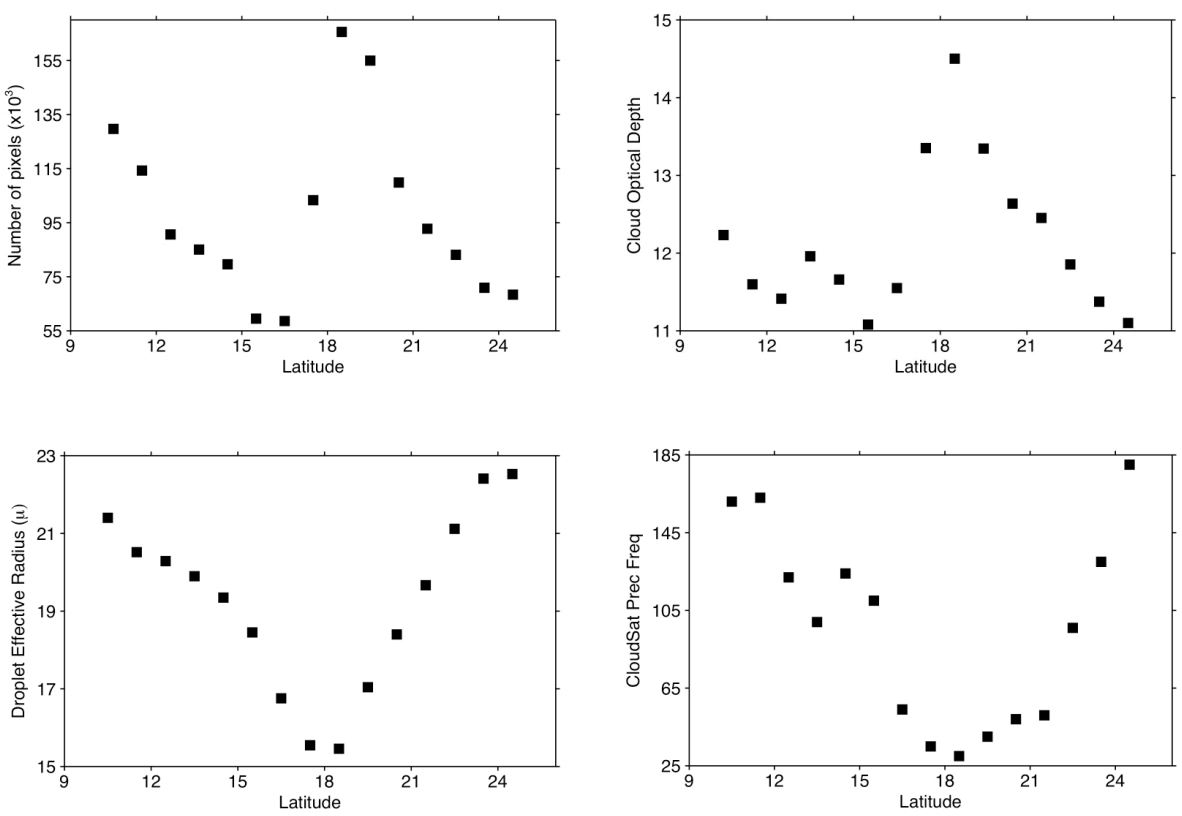

Fig. 7. Latitudinal variations of (clockwise) MODIS cloud number frequency (number of filtered cloud pixels), MODIS cloud optical depth, CloudSat precipitation frequency and MODIS droplet effective radius, averaged over the longitude band between $165^{\circ} \mathrm{W}$ and $175^{\circ} \mathrm{W}$. $\mathrm{Here}$ a direct longitude average is taken because the slight slant off the exact east-west direction of the aerosol plume makes little impact on sampling.
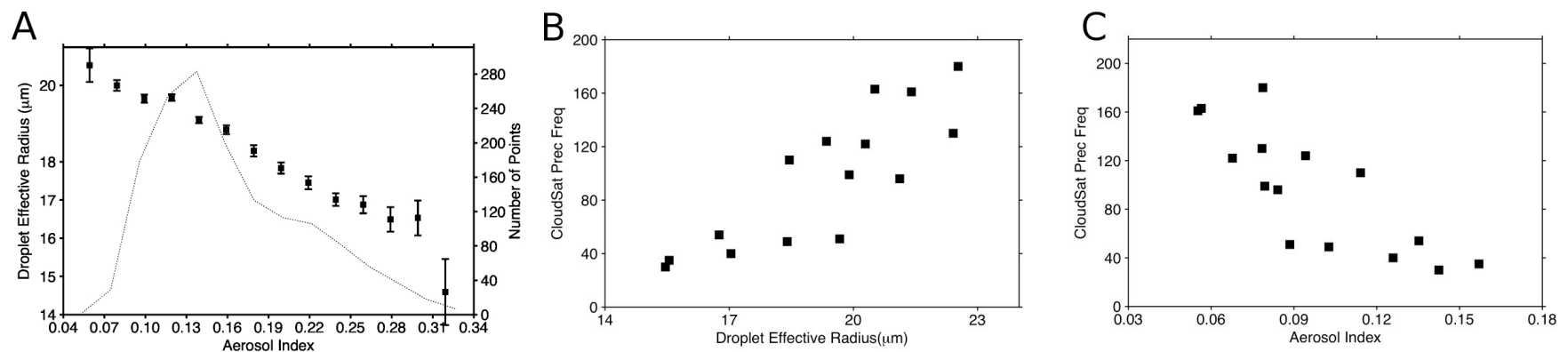

Fig. 8. (a) Cloud droplet effective radius $(\mu \mathrm{m})$ as a function of aerosol index for the region between $10^{\circ} \mathrm{N} \sim 25^{\circ} \mathrm{N}$ and $160^{\circ} \mathrm{W} \sim 180^{\circ} \mathrm{W}$. The right $y$-axis shows the number of points in each aerosol index bin (solid line). Each point represents the mean droplet effective radius for this aerosol index bin; (b) CloudSat precipitation frequency as a function of MODIS-derived droplet effective radius; (c) scatter plot of precipitation frequency against aerosol index. Each point (in $\mathbf{b}$ and $\mathbf{c}$ ) represents a zonal average of a $1^{\circ}$ latitudinal bin between $160^{\circ} \mathrm{W}$ and $170^{\circ} \mathrm{W}$. The total latitudinal span of the analysis covers from $10 \mathrm{~N}$ to $25^{\circ} \mathrm{N}$, and the temporal averaging period spans June-July-August 2008 .

shown in Fig. 7. We used MODIS level 2 cloud data and apply a threshold of 10 for cloud optical depth when selecting a pixel (see discussions above). Cloud precipitation occurrence frequency (Fig. 7d) is derived from CloudSat observations (Haynes et al., 2009). In this figure, we show that that latitudinal maxima in cloud occurrence and cloud optical depth is associated with a latitudinal minima in droplet size and precipitation occurrence. The maxima and minima of these fields are located at roughly $18^{\circ} \mathrm{N}$ inside the volcano tracks of Figs. 4 and 5, where aerosol concentration is increased by the volcano.
Cloud droplet size derived from MODIS is highly spatially correlated with aerosol index $\left(r^{2} \sim 0.8, p<0.01\right)$, and cloud precipitation occurrence frequency derived from CloudSat observations in the study region. is, in turn, highly spatially correlated $\left(r^{2}=0.7, p<0.01\right)$ with cloud droplet size, as shown in Fig. 8. Thus, CloudSat precipitation frequency is highly spatially negatively correlated with aerosol index (Fig. 8c). Each data point represents the seasonal average for a latitudinal bin in the selected region. Precipitation frequency is lowest inside the aerosol plume despite the higher cloud number frequency (Fig. 3d and 4) or cloud fraction. The cloud droplet size decreases by $2 \mu \mathrm{m}$ for every 0.1 
increase in aerosol index. The likelihood of warm precipitation for trade cumuli will be almost completely suppressed when droplet effective radius is smaller than $14 \mu \mathrm{m}$, corresponding to an aerosol index of 0.2. This agrees well with an emperically derived threshold value for initiation of warm drizzle (Rosenfeld, 2000).

We have used A-Train observations to demonstrate all three links in the chain of processes that leads to the cloud amount effect: a close association between reduction of cloud droplet size, suppression of precipitation, and increase of cloud fraction with enhanced aerosol concentration in a statistically significant way.

\subsection{Consequences of aerosol effects}

Theoretically the precipitation suppression can raise cloud tops (Pincus and Baker, 1994). We use CALIPSO data to detect cloud tops that are within the $2.5 \mathrm{~km}$ boundary layer. Focusing on nighttime data only because CALIPSO day time data are noisy, the boundary layer cloud tops within the sulfate plume are indeed generally higher than the background by $400-500 \mathrm{~m}$ (Fig. 9a). The boundary layer cloud top map thus creates another "volcano track" feature, which is spatially noiser because CALIPSO's spatial sampling is much sparser than that provided by an imager like MODIS. The difference between cloud tops in the volcano aerosol plume and just outside of the plume is consistent with that predicted by the simple model of Pincus and Baker (1994) and recent observations for ship tracks inside stratocumulus files (Christensen and Stephens, 2011). This increase in cloud top height is most likely due to the suppression of precipitation and enhanced entrainment at cloud top, a result of more and smaller cloud droplets. An alternative explanation may also be viable if the cloud invigoration effect (Koren et al., 2005; Yuan et al., 2011) also applies to shallow cumulus clouds.

Aerosols not only suppress the precipitation frequency (Figs. 7 and 8) but also decrease the precipitation rate (Fig. 9b) and this leads to perturbations of the energetics of the system. In Fig. 9b, the 2008 anomaly of precipitation for warm clouds is constructed based on the 2006-2009 climatology from CloudSat observations. The relative decrease in precipitation rate inside the sulfate plume is $30 \%-80 \%$ depending on the location, and the reduction is even larger for precipitation frequency. However, given the short duration of the CloudSat "climatology" and CloudSat's sparse spatial sampling these estimates are uncertain. Nevertheless, if we assume a $50 \%$ reduction in both the precipitation rate and frequency, the total precipitation amount will be decreased by $75 \%$. The areal mean climatology of CloudSat-derived warm rain rate over the study area is $0.4 \mathrm{~mm} \mathrm{day}^{-1}$. By taking into account only the warm precipitation, we roughly estimate that the reduction in latent heat transfer from ocean to atmosphere amounts to $\sim 8 \mathrm{~W} \mathrm{~m}^{-2}$ following a similar method in Snodgrass et al. (2009). Other factors such as the modification of humidity due to precipitation, evaporation
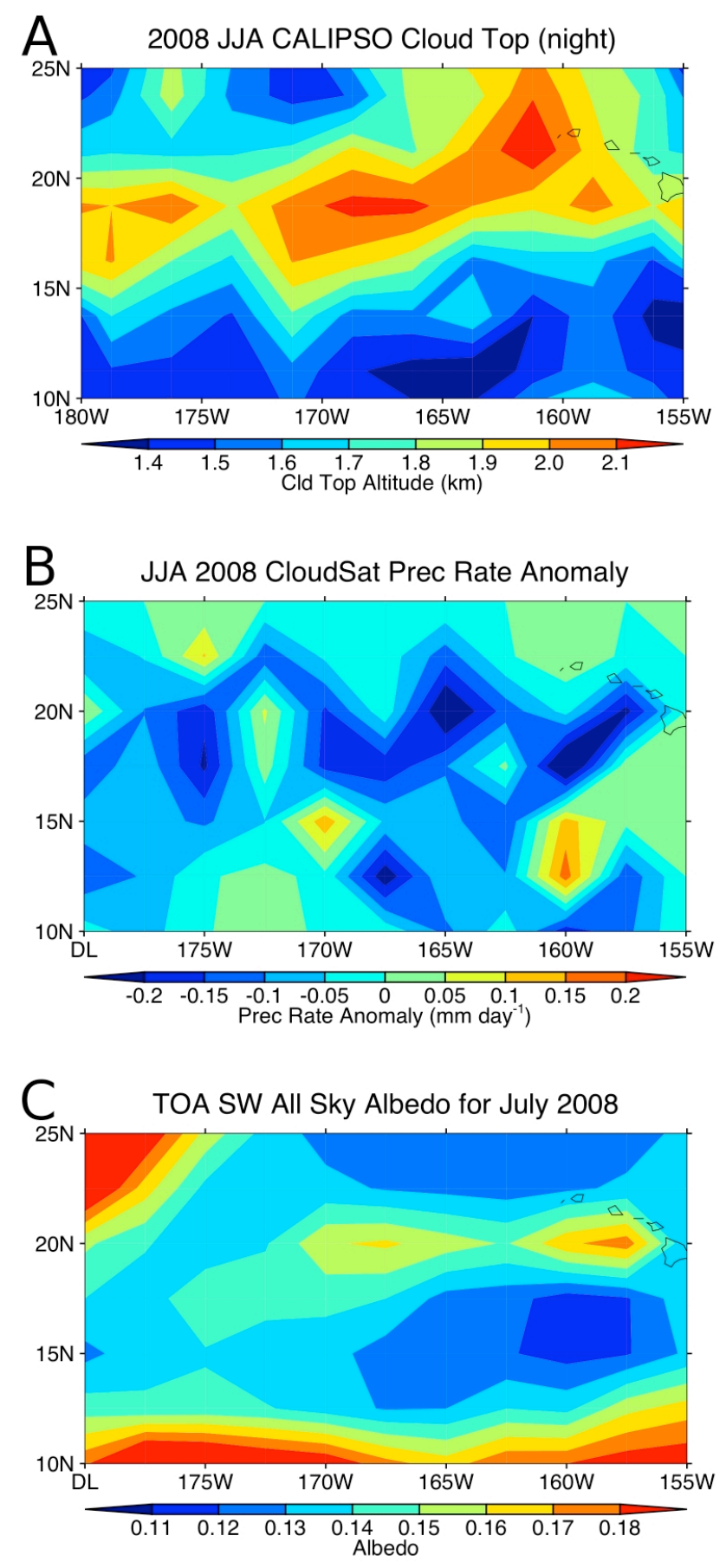

Fig. 9. (a) Seasonal mean CALIPSO cloud top height for June-JulyAugust of 2008 observed at night. Clouds are higher within the sulfate plume; (b) Observed CloudSat mean precipitation rate anomaly for 2008 relative to 2006-2009 climatology. A volcano track of precipitation reduction is noted; (c) Observed seasonal mean broadband albedo for July 2008 derived from the ERBE-like CERES product from the Aqua satellite. 
and sea surface feedbacks to cloud amount change are not accounted for in this rough estimate.

Radiatively, the simultaneous increases of cloud optical depth and cloud amount represent a scenario where the cloud amount effect reinforces the Twomey effect. Significant changes in shortwave albedo at the top of atmosphere are expected. The ideal conditions for this natural experiment allow us to take a holistic approach and not divide the aerosolaffected area into artificial "cloudy" and "cloud-free" subsets. Figure 9c shows a map of broadband albedo for July 2008 using the ERBE-like CERES product from the Aqua satellite under all sky conditions. Even with the coarse resolution a volcano track of high albedo is clearly noted in Fig. 9c. The planetary albedo increases by $0.02 \sim 0.05$ inside the sulfate plume compared to the background values of 0.12 , depending on the location. The secondary peak or minima of albedo inside the sulfate plume corresponds well with those of cloud optical depth, cloud droplet size and cloud frequency (Figs. 3 and 4). An increase in upwelling shortwave flux of about $20 \mathrm{~W} \mathrm{~m}^{-2}$ is observed by either estimating from the albedo change (Fig. 9c) or direct CERES monthly shortwave flux data (not shown). This is the aerosol total shortwave forcing resulting from aerosols modifying the whole aerosol-cloud continuum in this trade cumulus regime. Contributions of individual components are roughly estimated in the following.

Given the observed aerosol optical depth anomaly of 0.2 , the direct forcing is estimated to be $2 \mathrm{~W} \mathrm{~m}^{-2}$ based on the forcing efficiency calculated from MODIS aerosol retrievals (Remer and Kaufman, 2006) and observed cloud fraction. Aerosol indirect effects are thus responsible for the majority of the observed total forcing. Given the cloud fraction and cloud properties in the region, the Twomey effect contributes no more than $4 \mathrm{~W} \mathrm{~m}^{-2}$ (Platnick and Oreopoulos, 2008; Haywood et al., 2009) and cannot fully explain the strong total shortwave forcing. The increases in cloud amount are needed to explain the bulk of the aerosol total shortwave forcing inside the sulfate plume, which provides further evidence for the chain of processes that constitute the cloud amount effect. If those processes were not occurring, we could not explain the CERES observations.

\section{The wake effect and aerosol effects}

For detailed discussions on the air-sea interaction dynamics that drives the far field wake effect please refer to Xie et al. (2001). The wake effect manifests itself as a warm tongue feature in SST anomaly (Xie et al., 2001) that has similar shape to the volcano tracks discussed above although it is displaced further north. Two scenarios can be speculated that what we observe in this study is due to the wake effect instead of aerosol effect: in one, the observed variation in cloud properties could be caused by the wake effect while the volcanic degassing is just a coincidence; in the other, both

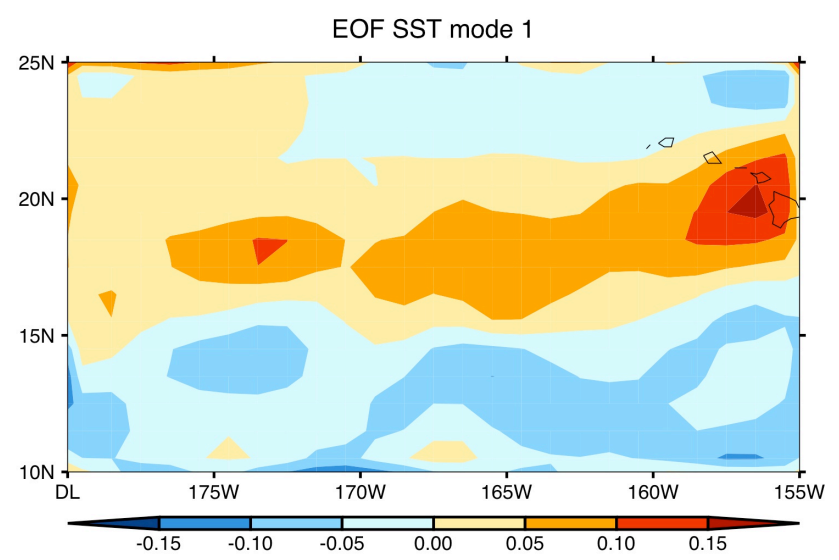

Fig. 10. High-pass filtered Sea Surface Temperature (SST) Empirical Orthogonal Function (EOF) mode 1. Data are taken from the years 2000-2010.

aerosol and cloud could be affected by the wake effect to produce artificial correlation between them (Loeb and Schuster, 2008; Yuan et al., 2008). We examine these possibilities in the following.

We first note that wake effect is only a small anomaly to the mean flow (Xie et al., 2001). The anomaly introduced is on the order of $1 \mathrm{~m} \mathrm{~s}^{-1}$ or less in wind speed and of $0.1 \mathrm{~K}$ in SST, with even smaller yearly variations. Such small anomalies would not significantly affect the distribution of aerosols because the mean flow (on the order of $10 \mathrm{~m} \mathrm{~s}^{-1}$ ) dominates aerosol transport. Second, the aerosol source strength is very unlikely affected by the wake effect because variability of the aerosol source is mainly related to the human and natural (mainly volcanic) emissions over the Big Island. These facts make the second scenario very unlikely. Moreover, the wakeeffect is expected to produce more precipitation downwind of the Big Island (Kidd and McGregor, 2007), which contradicts our observed precipitation reduction inside the wake/ volcano track, a clear sign of aerosols creating a microphysical effect.

Next, we present quantitative evidence that negates the wake-effect hypothesis and supports aerosol effect hypothesis using empirical orthogonal function (EOF) (Wilks, 2005) analysis. EOF analysis decomposes time-varying meteorological, oceanic, aerosol and cloud fields into spatial patterns and associated time series of these patterns. The modes of EOF and associated principal components (time series of amplitude of EOF modes) reveal the dominant spatial patterns and associated temporal variations. Before computing the EOF modes, we first remove climatological means from the summertime data and apply area weights to each grid.

Following Xie et al. (2001), we first apply a high-pass filter to the SST field and compute the EOFs for the highpass filtered data. The EOF mode 1 for the filtered SST is shown in Fig. 10. The spatial pattern of this EOF mode 
Table 1. Correlation coefficients for principal components of each cloud parameter against either aerosol concentration or filtered Sea Surface Temperature (SST). While none of the correlations between filtered SST and cloud properties are statistically significant, all correlations between cloud properties and aerosol index are significant at the $97 \%$ confidence level or better.

\begin{tabular}{llll}
\hline & Cloud optical depth & Cloud droplet radius & Cloud fraction \\
\hline Aerosol & $0.898(p<0.001)$ & $-0.867(p<0.001)$ & $0.683(p<0.03)$ \\
Filtered SST & 0.108 & $0.4(p>0.2)$ & 0.107 \\
\hline
\end{tabular}

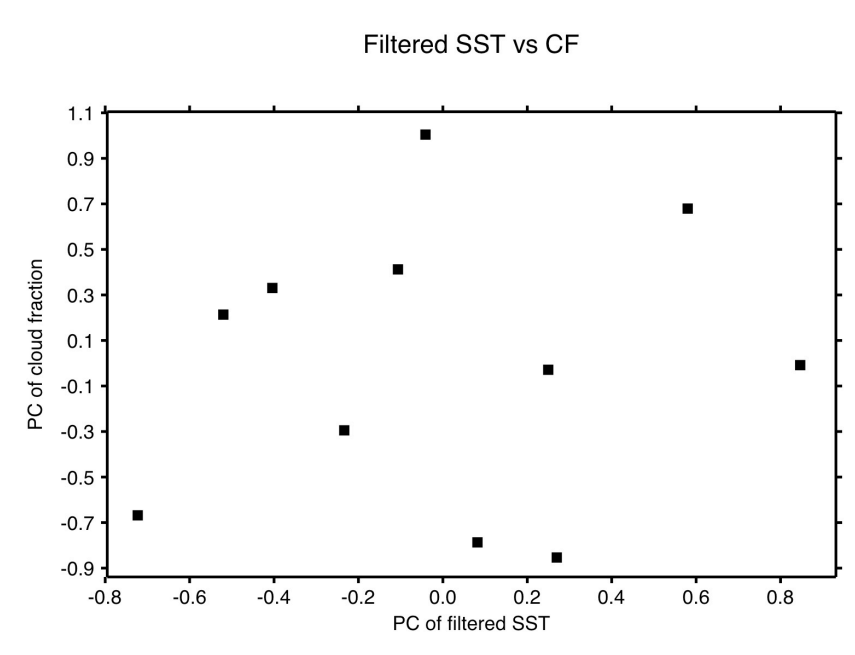

Fig. 11. Scatter plot of the principal component of filtered SST EOF mode 1 against that of cloud fraction, showing no correlation between them. 2008 has the highest value of cloud fraction principal component while the filtered SST is close to the mean value.

is similar in shapes to volcano tracks in cloud and aerosol fields discussed above. However, the temporal variations in the strength of this SST pattern cannot explain any variations in cloud or aerosol fields, as suggested by low correlations between principal components of cloud variables and that of SST (Table 1 and Fig. 11). As an example, the correlation coefficient between principal components of cloud fraction and filtered SST is $r=0.107$. Similar low values of correlation coefficients are computed for other fields against the filtered SST (Table 1). We also examined the bulk SST (not filtered) and neither the spatial nor the temporal variability can explain any cloud property variations.

Similarly we examined meteorological fields from MERRA, including surface wind speed, $850 \mathrm{mb}$ temperature, surface temperature, and relative humidity. None of the temporal variations in these variables are capable of explaining the cloud property variations observed by MODIS. For example, in JJA 2008 surface temperature across the domain is actually colder than usual, which is in line with an overall lower than usual cloud fraction in this year. The relative humidity field also indicates that the atmosphere in 2008 is drier than the climatological mean (Fig. 12). The dry and cold conditions are unfavorable for cloud formation. How- ever, despite these unfavorable conditions cloud fraction inside the volcano tracks is statistically higher in 2008 than the climatological mean. The results suggest that variations in meteorological conditions are not capable of explaining the variations in cloud fraction, cloud microphysical and optical properties. Factors other than synoptic scale meteorology or SST have affected temporal and spatial variations of cloud properties.

We examine the aerosol hypothesis using similar EOF analysis. We compute the EOFs of the aerosol index fields and show the mode 1 EOF in Fig. 13. This pattern clearly shows a plume originating from the Big Island. This EOF mode is statistically significantly correlated in space $(r=0.4$, $p<0.01)$ with the first EOF mode of cloud fraction. The principal component of aerosol is also well correlated $(r=0.682$, $p<0.03$ ) with that of cloud fraction, which is statistically significant at above the $95 \%$ level (even if 2008 is left out of the analysis). We do similar exercises to cloud droplet effective radius and cloud optical depth fields (precipitation record from CloudSat is too short to make meaningful statistical tests). Their EOF mode 1 patterns are spatially correlated with that of aerosol index (aerosol optical depth as well) at above the $99 \%$ significance level. More importantly, the principal components of these variables are well correlated with aerosol fields, suggesting a strong control of cloud droplet size by aerosol concentration (see Table 1).

We have thus shown that the temporal variability of the wake effect (Xie et al., 2001; Hafner and Xie, 2003) cannot explain the observed temporal variability of cloud or aerosols properties. Variability of wind, temperature, and humidity could not explain the temporal variation in cloud fraction either. Only variations in aerosols are well correlated with the cloud fraction as well as microphysical and optical property variations. These analyses point to the conclusion that what we observe is a result of physical interactions among aerosol, clouds, and precipitation rather than a mere coincidence.

\section{Discussion and concluding remarks}

It appears that the suppression of precipitation may be the key to the observed increase in cloud fraction that is associated with increase in aerosol concentration: the addition of aerosols impedes the autoconversion of cloud water to rain and increases overall cloud coverage, as shown in the 


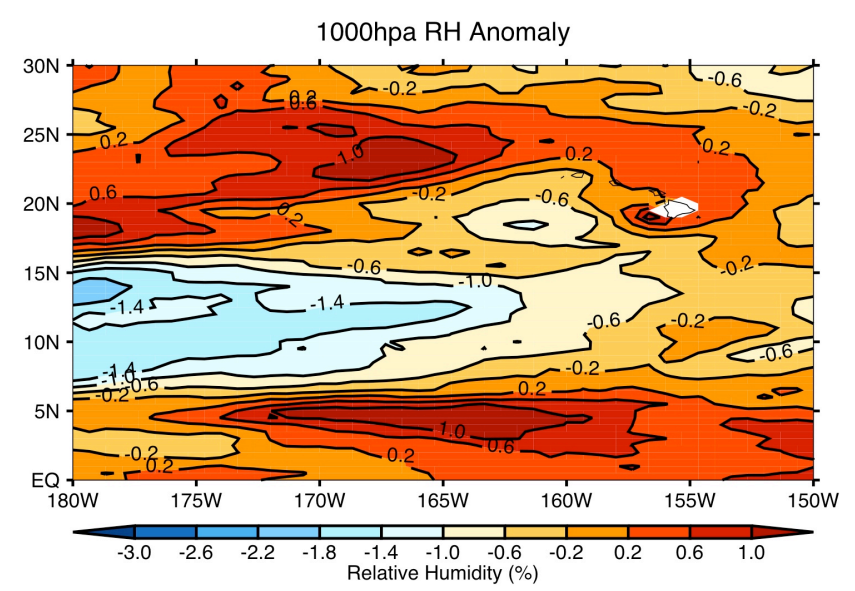

Fig. 12. Relative humidity anomaly in JJA, 2008 at $1000 \mathrm{hPa}$ calculated from the NASA Modern Era Retrospective-Analysis for Research and Applications (MERRA) data set. The area downwind of the Hawaiian Islands is generally drier relative to climatology.

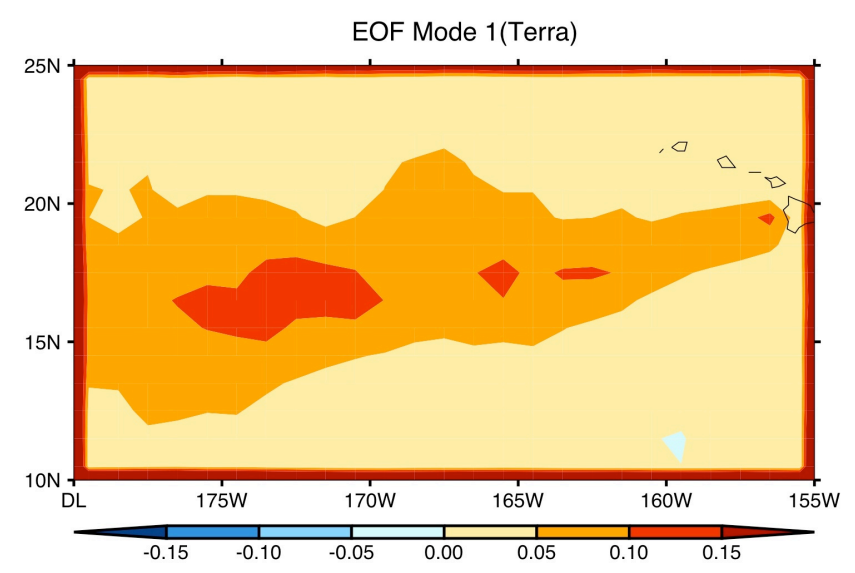

Fig. 13. The EOF mode 1 of aerosol index. A pattern of a plume emerging from the Big Island is apparent and it provides the dominant variability in aerosol. A similar pattern is observed for aerosol optical depth EOF mode 1.

schematic (Fig. 14). Browsing through visible MODIS images we noted that volcanic plume events are often associated with larger cloud patches. We examined this possiblity by studying the size of these cloud patches using the MODIS cloud mask (procedure is described in Sect. 3). We find that the average cloud patch size in 2008 increases, especially for larger clouds, relative to all other years. Also in 2008, the mean cloud patch size inside the aerosol plume is 71 (number of pixels), much higher than the background value of about 55 , which is also close to mean values in other years. These observations seem to suggest clouds change their organization such that there is a more frequent occurrence of large cloud patches under polluted conditions. However, we note that the utility of cloud patch size derived from $1-\mathrm{km}$ MODIS cloud mask may be limited due to the issue of par-

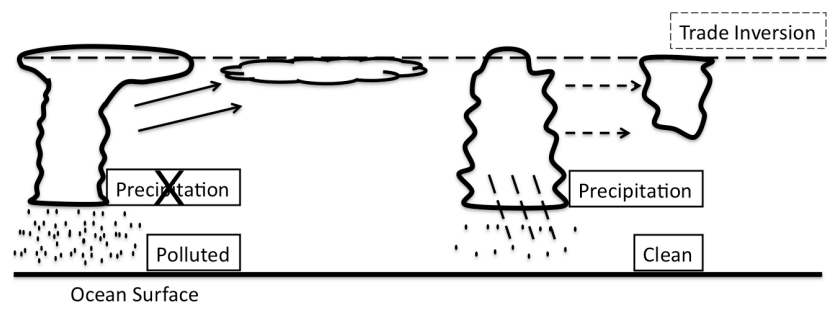

Fig. 14. A schematic depicting the different evolution of polluted, non-precipitating and clean, precipitating trade cumuli.

tially cloudy pixels even though we purposely avoided looking at clouds smaller than 5. Higher resolution (on the order of $10 \mathrm{~m}$ ) data are needed for this purpose (Koren et al., 2008). Nevertheless, a few past observational studies (with high resolution data) seem to suggest that polluted trade cumuli are larger. For example, McFarquhar et al. (2004) found that over the Indian Ocean relatively more large clouds are associated with episodes of polluted air. Their conclusion is also supported by results from Dey et al. (2011) although they attributed this size shift to evaporation of small clouds by the aerosol semi-direct effect. While both studies suggested possible difference in air mass properties associated with clean and polluted espisodes we are here working in the same air mass since introduction of the volcanic emissions does not change the temperature, humidity or stability of the atmosphere significantly.

To better understand the exact mechnisms of the microand macro- physical changes in trade cumuli induced by aerosols, large-eddy model simulations with detailed microphyiscal schemes are needed (Xue et al., 2008; Jiang et al., 2009; Koren et al., 2009). Dedicated field-campaigns shall complement smaller scale observations to the results presented here and offer further clues for modeling efforts.

Conventionally, trade cumuli are thought to be radiatively less important in terms of determining the planetary albedo due to their smaller cloud fraction as compared with stratocumulus even though they are present over a larger fraction of the ocean. However, our findings indicate aerosols can remarkably leverage their total negative shortwave radiative forcing by a factor of almost 10 relative to their direct forcing through interacting with trade cumuli. This high leverage highlights the potential of trade cumuli to change the radiative balance when interacting with aerosols (Norris and Slingo, 2009). Moreover, trade cumuli are critical in preconditioning the boundary layer for tropical deep convection. Precipitation suppression in trade cumuli reduces latent heat transfer from ocean to atmosphere. Entrainment mixing that possibly leads to an increase in cloud top height and amount may modify the moisture structure of the boundary layer. These changes together with the strong negative aerosol total shortwave radiative forcing will affect preconditioning of the boundary layer and ultimately tropical convection (Wyant et 
al., 1997). Aerosol effects on trade cumuli can thus affect the hydrological cycle indirectly by modifying boundary layer properties. This secondary impact can only be assessed and studied by a global model.

The response of trade cumuli to aerosol input documented here provides the first set of large-scale observational constraints on model parameterizations of aerosol indirect effects (Forster et al., 2007). With the observational constraints, better representation of indirect effects in climate models can have an observational anchor. This improved representation of indirect effects will improve our understanding of the anthropogenic aerosol total forcing in the past and narrow uncertainties related to aerosol forcing in climate change predictions (Forster et al., 2007). For example, the past economic development induced aerosol increase by industrial pollution and biomass burning upwind of trade cumulus cloud areas could have strongly masked greenhouse warming at regional scales. In addition, the strong sensitivity of the trade cumulus regime to aerosol input documented here sheds new light on the importance of non-eruptive volcanoes to the Earth's energy balance and hydrological system. Such importance has been largely overlooked due to the relatively short lifetime of tropospheric sulfates and omission of aerosol effect on clouds (Robock, 2000). With the new understanding, we argue that a few continuously degassing volcanoes could affect large portions of the tropics, the heart of the general circulation engine. Moreover, we note interesting potential competing effects in the case of absorbing aerosols such as smoke: the semi-direct effect would tend to decrease cloud fraction while the cloud amount effect does the opposite. The competing effects may offer a potential explanation for some of the discrepancy in the literature regarding absorbing aerosol effect on cloud fraction (Ackerman et al., 2000; Norris, 2001). The high radiative sensitivity of trade cumulus regimes to aerosols also offers an attractive option when researching climate mitigation strategies to counteract gas-induced warming (Latham et al., 2008; Hegerl and Solomon, 2009; Jones et al., 2009; Robock et al., 2010).

To sum up, the aerosol effects appear as volcano tracks of reduced cloud droplet size, enhanced cloud optical depth, suppressed precipitation, elevated cloud tops and increased cloud fraction in a natural, ideal experiment. These aerosol effects lead to a strong total radiative forcing, as large as $20 \mathrm{Wm}^{2}$. Our results are among the first observations of the cloud amount effect at large spatial (on the order of $10^{6} \sim 10^{7} \mathrm{~km}^{2}$ ) and long temporal scales (seasonal) since the original hypothesis (Albrecht, 1989).

Acknowledgements. 'We thank three anonymous reviewers and the editor Yves Balkanski for their comments and suggestions. The research was supported by NASA's IDS and Radiation Science programs. We also wish to acknowledge many science product teams of various A-Train sensors.

Y. Balkanski

\section{References}

Ackerman, A. S., Toon, O. B., Stevens, D. E., Heymsfield, A. J., Ramanathan, V., and Welton, E. J.: Reduction of tropical cloudiness by soot, Science, 288, 5468, 1042-1047, 2000.

Ackerman, A. S., Kirkpatrick, M. P., Stevens, D. E., and Toon, O. B.: The impact of humidity above stratiform clouds on indirect aerosol climate forcing, Nature, 432, 7020, doi:10.1038/nature03174, 2004.

Albrecht, B. A.: Aerosols, Cloud Microphysics, and Fractional Cloudiness, Science, 245, 4923, doi:10.1126/science.245.4923.1227, 1989.

Andreae, M. O., Rosenfeld, D., Artaxo, P., Costa, A. A., Frank, G. P., Longo, K. M., and Silva-Dias, M. A. F.: Smoking rain clouds over the Amazon. Science, 303, 5662, 1337-1342, 2004.

Anderson, T. L., Charlson, R. J., Schwartz, S. E., Knutti, R., Boucher, O., Rodhe, H., and Heintzenberg, J.: Climate forcing by aerosols -a hazy picture, Science, 300, 5622, 1103-1104, 2003.

Betts, A. K. and Albrecht, B. A.: Conserved variable analysis of the convective boundary-layer thermodynamic structure over the Tropical Ocean, J. Atmos. Sci., 44(1), 83-99, 1987.

Brenguier, J. L., Pawlowska, H., and Schuller, L.: Cloud microphysical and radiative properties for parameterization and satellite monitoring of the indirect effect of aerosol on climate, J. Geophys. Res.-Atmos., 108(D15), 8632 , doi:10.1029/2002JD002682, 2003.

Bretherton, C. S., Blossey, P. N., and Uchida, J., Cloud droplet sedimentation, entrainment efficiency, and subtropical stratocumulus albedo, Geophys. Res. Lett., 34(3), L03813, doi:10.1029/2006GL027648, 2007.

Charlson, R. J., Ackerman, A. S., Bender, F. A., Anderson, T. L., and Liu, Z., On the climate forcing consequences of the albedo continuum between cloudy and clear air, Tellus B, 59(4), 715727, doi:10.1111/j.1600-0889.2007.00297.x, 2007.

Christensen, M., and Stephens, G., Microphysical and macrophysical responses of marine stratocumulus polluted by underlying ships: Evidence of cloud deepening, J. Geophys. Res.-Atmos., 116, D03201, doi:10.1029/2010JD014638, 2011.

Dey, S., Di Girolamo, L., Zhao, G., Jones, A. L., and Mcfarquhar, G.: Satellite-observed relationships between aerosol and tradewind cumulus cloud properties over the Indian Ocean, Geophys Res Lett, 38, L01804, doi:10.1029/2010GL045588, 2011.

Feingold, G. and Siebert, H.: Cloud-aerosol interactions from the micro to the cloud scale, Clouds in Perturbed Climate system: their relationship to energy balance, atmospheric dynamics and precipitation, MIT Press, Cambridge, MA, USA, 2009.

Feingold, G., Kreidenweis, S. M., Stevens, B., and Cotton, W. R.: Numerical simulations of stratocumulus processing of cloud condensation nuclei through collision-coalescence, J. Geophys. Res. Atmos., 101(D16), 21391-21402, 1996.

Feingold, G., Koren, I., Wang, H., Xue, H., and Brewer, W. A.: Precipitation-generated oscillations in open cellular cloud fields, Nature, 466, 7308, doi:10.1038/nature09314, 2010.

Forster, P., Ramaswamy, V., Artaxo, P., Berntsen, T., Betts, R., Fahey, D. W., Haywood, J., Lean, J., Lowe, D. C., Myhre, G., Nganga, J., Prinn, R., Raga, G., Schulz, M., and Dorland, R. V.: Changes in Atmospheric Constituents and in Radiative Forcing, The Physical Science Basis. Contribution of Working Group I to the Fourth Assessment Report of the Intergovernmental Panel on 
Climate Change, Cambridge University Press, Cambridge, UK and New York, USA, 2007.

Gasso, S.: Satellite observations of the impact of weak volcanic activity on marine clouds, J. Geophys. Res. Atmos., 113(D14), D14S19, doi:10.1029/2007JD009106, 2008.

Hafner, J. and Xie, S. P.: Far-field simulation of the Hawaiian wake: Sea surface temperature and orographic effects, J Atmos Sci, 60(24), 3021-3032, 2003.

Haynes, J. M., L'ecuyer, T. S., Stephens, G. L., Miller, S. D., Mitrescu, C., Wood, N. B., and Tanelli, S.: Rainfall retrieval over the ocean with spaceborne W-band radar. J. Geophys. Res. Atmos., 114, D00A22, doi:10.1029/2008JD009973, 2009.

Haywood, J., Donner, L. J., Jones, A., and Golaz, J.: Global Indirect Radiative Forcing Caused by Aerosols IPCC (2007) and Beyond, Clouds in the perturbed climate system: their relationship to energy balance, atmospheric dynamics and precipitation, MIT press, Cambridge, MA, USA, 2009.

Hegerl, G. C. and Solomon, S.: Risks of Climate Engineering. Science, 325, 5943, 955-956, doi:10.1126/science.1178530, 2009.

Heymsfield, A. J. and Mcfarquhar, G. M., Microphysics of INDOEX clean and polluted trade cumulus clouds, J. Geophys. Res. Atmos., 106(D22), 28653-28673, 2001.

Jiang, H., Feingold, G., and Koren, I.: Effect of aerosol on trade cumulus cloud morphology, J. Geophys. Res. Atmos., 114, D11209, doi:10.1029/2009JD011750, 2009.

Jones, A., Haywood, J., and Boucher, O.: Climate impacts of geoengineering marine stratocumulus clouds, J. Geophys. Res. Atmos., 114, D10106, doi:10.1029/2008JD011450, 2009.

Kaufman, Y. J. and Koren, I., Smoke and pollution aerosol effect on cloud cover, Science, 313, 5787, doi:10.1126/science.1126232, 2006.

Kidd, C. and Mcgregor, G.: Observation and characterisation of rainfall over Hawaii and surrounding region from the Tropical Rainfall Measuring Mission, Int. J. Climatol., 27(4), 541-553, doi:10.1002/joc.1414, 2007.

Koren, I., Kaufman, Y. J., Remer, L. A., and Martins, J. V.: Measurement of the effect of Amazon smoke on inhibition of cloud formation, Science, 303, 1342-1345, 2004.

Koren, I., Kaufman, Y. J., Rosenfeld, D., Remer, L. A., and Rudich, Y.: Aerosol invigoration and restructuring of Atlantic convective clouds, Geophys. Res. Lett., 32(14), L14828, doi:10.1029/2005GL023187, 2005.

Koren, I., Remer, L. A., Kaufman, Y. J., Rudich, Y., and Martins, J. V.: On the twilight zone between clouds and aerosols, Geophys. Res. Lett., 34(8), L08805, doi:10.1029/2007GL029253, 2007.

Koren, I., Oreopoulos, L., Feingold, G., Remer, L. A., and Altaratz, O.: How small is a small cloud? Atmos. Chem. Phys., 8, 38553864, doi:10.5194/acp-8-3855-2008, 2008.

Koren, I., Feingold, G., Jiang, H., and Altaratz, O.: Aerosol effects on the inter-cloud region of a small cumulus cloud field, Geophys. Res. Lett., 36, L14805, doi:10.1029/2009GL037424, 2009.

Latham, J., Rasch, P., Chen, C., Kettles, L., Gadian, A., Gettelman, A., Morrison, H., Bower, K., and Choularton, T.: Global temperature stabilization via controlled albedo enhancement of lowlevel maritime clouds, Philos. T. R. Soc. A, 366, 3969-3987, doi:10.1098/rsta.2008.0137, 2008

Loeb, N. G. and Schuster, G. L.: An observational study of the relationship between cloud, aerosol and meteorology in broken low-level cloud conditions. J. Geophys. Res. Atmos., 113(D14),
D14214, doi:10.1029/2007JD009763, 2008

Lohmann, U., Koren, I., and Kaufman, Y. J.: Disentangling the role of microphysical and dynamical effects in determining cloud properties over the Atlantic, Geophys. Res. Lett., 33(9), L09802, doi:10.1029/2005GL024625, 2006.

Lu, M. L., and Seinfeld, J. H.: Study of the aerosol indirect effect by large-eddy simulation of marine stratocumulus, J. Atmos. Sci., 62(11), 3909-3932, 2005.

Marshak, A., Platnick, S., Varnai, T., Wen, G. Y., and Cahalan, R. F.: Impact of three-dimensional radiative effects on satellite retrievals of cloud droplet sizes, J. Geophys. Res. Atmos., 111(D9), D09207, doi:10.1029/2005JD006686, 2006.

Mauger, G. S. and Norris, J. R.: Meteorological bias in satellite estimates of aerosol-cloud relationships, Geophys. Res. Lett., 34(16), L16824, doi:10.1029/2007GL029952, 2007.

Mccormic, R. and Ludwig, J. H.: Climate modification by atmospheric aerosols, Science, 156, 1358-1359, 1967.

Mcfarquhar, G. M., Platnick, S., Di Girolamo, L., Wang, H. K., Wind, G., and Zhao, G. Y.: Trade wind cumuli statistics in clean and polluted air over the Indian Ocean from in situ and remote sensing measurements, Geophys. Res. Lett., 31(21), L21105, doi:10.1029/2004GL020412, 2004.

Nakajima, T., Higurashi, A., Kawamoto, K., and Penner, J. E.: A possible correlation between satellite-derived cloud and aerosol microphysical parameters, Geophys. Res. Lett., 28(7), 11711174, 2001.

Norris, J. R.:, Has northern Indian Ocean cloud cover changed due to increasing anthropogenic aerosol?, Geophys. Res. Lett., 28(17), 3271-3274, 2001.

Norris, J. R. and Slingo, A.: Trends in observed cloudiness and Earth's radiation budget: what do we not know and what do we need to know?. Clouds in the Perturbed Climate system: their relationship to energy balance, atmospheric dynamics and precipitation, MIT Press, Cambridge, MA, USA, 2009.

Pincus, R. and Baker, M. B.: Eeffect of precipitation on the albedo susceptibility of clouds in the marine boundary-layer, Nature, 372, 250-252, 1994.

Platnick, S. and Oreopoulos, L.: Radiative susceptibility of cloudy atmospheres to droplet number perturbations: 1. Theoretical analysis and examples from MODIS, J. Geophys. Res. Atmos., 113(D14), D14S20, doi:10.1029/2007JD009654, 2008.

Platnick, S., King, M. D., Ackerman, S. A., Menzel, W. P., Baum, B. A., Riedi, J. C., and Frey, R. A.: The MODIS cloud products: Algorithms and examples from Terra, IEEE Trans. Geosci. Remote Sens., 41(2), 459-473, doi:10.1109/TGRS.2002.808301, 2003.

Quaas, J., Ming, Y., Menon, S., Takemura, T., Wang, M., Penner, J. E., Gettelman, A., Lohmann, U., Bellouin, N., Boucher, O., Sayer, A. M., Thomas, G. E., Mccomiskey, A., Feingold, G., Hoose, C., Kristjansson, J. E., Liu, X., Balkanski, Y., Donner, L. J., Ginoux, P. A., Stier, P., Grandey, B., Feichter, J., Sednev, I., Bauer, S. E., Koch, D., Grainger, R. G., Kirkevag, A., Iversen, T., Seland, O., Easter, R., Ghan, S. J., Rasch, P. J., Morrison, H., Lamarque, J., Iacono, M. J., Kinne, S., and Schulz, M.: Aerosol indirect effects - general circulation model intercomparison and evaluation with satellite data, Atmos. Chem. Phys., 9, 86978717, doi:10.5194/acp-9-8697-2009, 2009.

Rauber, R. M., Stevens, B., Ochs, H. T., Knight, C., Albrecht, B. A., Blyth, A. M., Fairall, C. W., Jensen, J. B., Lasher-Trapp, S G., Mayol-Bracero, O. L., Vali, G., Anderson, J. R., Baker, B. 
A., Bandy, A. R., Burnet, E., Brenguier, J. L., Brewer, W. A., Brown, P. R. A., Chuang, P., Cotton, W. R., Girolamo, L. D., Geerts, B., Gerber, H., Goke, S., Gomes, L., Heikes, B. G., Hudson, J. G., Kollias, P., Lawson, R. P., Krueger, S. K., Lenschow, D. H., Nuijens, L., O'sullivan, D. W., Rilling, R. A., Rogers, D. C., Siebesma, A. P., Snodgrass, E., Stith, J. L., Thornton, D. C., Tucker, S., Twohy, C. H., and Zuidema, P.: Rain in shallow cumulus over the ocean - The RICO campaign, B. Am. Meteorol. Soc., 88(12), 1912-1928, doi:10.1175/BAMS-88-12-1912, 2007.

Remer, L. A. and Kaufman, Y. J.: Aerosol direct radiative effect at the top of the atmosphere over cloud free ocean derived from four years of MODIS data, Atmos. Chem. Phys., 6, 237-253, doi:10.5194/acp-6-237-2006, 2006.

Remer, L. A., Kaufman, Y. J., Tanre, D., Mattoo, S., Chu, D. A., Martins, J. V., Li, R. R., Ichoku, C., Levy, R. C., Kleidman, R. G., Eck, T. F., Vermote, E., and Holben, B. N.: The MODIS aerosol algorithm, products, and validation, J. Atmos. Sci., 62(4), 947973, 2005.

Riehl, H., Yeh, T. C., Malkus, J. S., and Laseur, N. E.: The northeast trade of the Pacific Ocean, Q. J. Roy. Meteorol. Soc., 77, 598-626, 1951

Robock, A.: Volcanic eruptions and climate, Rev. Geophys., 38(2), 191-219, 2000.

Robock, A., Bunzl, M., Kravitz, B., and Stenchikov, G. L.: A Test for Geoengineering?, Science, 327, 530-531, doi:10.1126/science.1186237, 2010.

Rosenfeld, D.: TRMM observed first direct evidence of smoke from forest fires inhibiting rainfall, Geophys. Res. Lett., 26(20), 3105-3108, 1999.

Rosenfeld, D.: Suppression of rain and snow by urban and industrial air pollution, Science, 287, 1793-1796, 2000.

Snodgrass, E. R., Di Girolamo, L., and Rauber, R. M.: Precipitation Characteristics of Trade Wind Clouds during RICO Derived from Radar, Satellite, and Aircraft Measurements, J. Appl. Meteorol. Clim., 48(3), 464-483, doi:10.1175/2008JAMC1946.1, 2009.

Stephens, G. L., Vane, D. G., Boain, R. J., Mace, G. G., Sassen, K., Wang, Z. E., Illingworth, A. J., O'connor, E. J., Rossow, W. B., Durden, S. L., Miller, S. D., Austin, R. T., Benedetti, A., and Mitrescu, C.: The cloudsat mission and the a-train - A new dimension of space-based observations of clouds and precipitation. B. Am. Meteorol. Soc., 83(12), 1771-1790, doi:10.1175/BAMS83-12-1771, 2002.

Stevens, B. and Feingold, G.: Untangling aerosol effects on clouds and precipitation in a buffered system, Nature, 461, 607-613, doi:10.1038/nature08281, 2009.
Stevens, B., Cotton, W. R., Feingold, G., and Moeng, C. H., Large-eddy simulations of strongly precipitating, shallow, stratocumulus-topped boundary layers, J. Atmos. Sci., 55(24), 3616-3638, 1998.

Twomey, S.: Influence of pollution on shortwave albedo of clouds, J. Atmos. Sci., 34(7), 1149-1152, 1977.

Wen, G. Y., Marshak, A., and Cahalan, R. F.: Impact of 3-D clouds on clear-sky reflectance and aerosol retrieval in a biomass burning region of Brazil, IEEE Geosci. Remote Sens., 3, 169-172, doi:10.1109/LGRS.2005.861386, 2006.

Wielicki, B. A., Barkstrom, B. R., Harrison, E. F., Lee, R. B., Smith, G. L., and Cooper, J. E.: Clouds and the earth's radiant energy system (CERES): An earth observing system experiment, B. Am. Meteorol. Soc., 77(5), 853-868, 1996.

Wilks, D. S.: Statistical Methods in the Atmospheric Sciences, ACADEMIC PRESS, Maryland Heights, MO, 2005.

Wood, R.: Cancellation of aerosol indirect effects in marine stratocumulus through cloud thinning. J Atmos Sci, 64(7), 26572669, doi:10.1175/JAS3942.1, 2007.

Wyant, M. C., Bretherton, C. S., Rand, H. A., and Stevens, D. E.: Numerical simulations and a conceptual model of the stratocumulus to trade cumulus transition, J. Atmos. Sci., 54(1), 168192, 1997.

Xie, S. P., Liu, W. T., Liu, Q. Y., and Nonaka, M.: Far-reaching effects of the Hawaiian islands on the Pacific Ocean-atmosphere system, Science, 292, 2057-2060, 2001.

Xue, H., Feingold, G., and Stevens, B.: Aerosol effects on clouds, precipitation, and the organization of shallow cumulus convection, J. Atmos. Sci., 65(2), 392-406, doi:10.1175/2007JAS2428.1, 2008.

Xue, H. W. and Feingold, G.: Large-eddy simulations of trade wind cumuli: Investigation of aerosol indirect effects, J. Atmos. Sci., 63(6), 1605-1622, 2006.

Yuan, T., Li, Z., Zhang, R., and Fan, J.: Increase of cloud droplet size with aerosol optical depth: An observation and modeling study, J. Geophys. Res. Atmos., 113(D4), D04201, doi:10.1029/2007JD008632, 2008.

Yuan, T., Remer, L. A., Pickering, K. E., and Yu, H.: Observational evidence of aerosol enhancement of lightning activity and convective invigoration, Geophys. Res. Lett., 38, L04701, doi:10.1029/2010GL046052, 2011

Zhao, G. and Di Girolamo, L.: Statistics on the macrophysical properties of trade wind cumuli over the tropical western Atlantic, J. Geophys. Res. Atmos., 112, D10204, doi:10.1029/2006JD007371, 2007. 